\title{
Electrodessication of Sebaceous Cyst - A Case Report
}

\author{
Authors \\ Raji P. Philipose, Srikanth S., Krishnan S. \\ Dept. of Dermatology, Venereology and Leprology, \\ Mahatma Gandhi Medical College \& Research Institute, Pondicherry, India
}

\begin{abstract}
Sebaceous cyst is a keratin filled cyst that occurs in hair bearing areas of the body like scalp, face, neck, back and scrotum. There are various modalities of treatment for these cysts, the commonest being surgical excision. We report a 30 year old male who presented to us with multiple sebaceous cysts over his scrotum. We aimed to remove the cysts with no bleeding and minimal scar formation. Electrodessication of the cysts was done and it yielded very good result.
\end{abstract}

Keywords: Sebaceous cyst, Epidermoid cyst, Electrodessication.

\section{INTRODUCTION}

Sebaceous cyst (syn: Epidermoid cyst) is a keratin filled epithelial lined cyst. It is a small, domeshaped cyst filled with a thick, greasy, cheese like substance. ${ }^{1}$ It occurs commonly in hair-bearing areas like the scalp, face, neck, back and scrotum. ${ }^{2}$ Several methods of treatment have been employed for the treatment of these cysts. We report a case of sebaceous cyst treated with Electrodessication.

\section{CASE REPORT}

A 30 year old male presented to our OPD with complaints of multiple, painless lesions over his scrotum since 4 years (Fig.1). He gives history of minimal increase in size of the lesions. There was no history of discharge. On examination, multiple non- tender, firm, dome shaped whitish nodules, varying from $2-4 \mathrm{~mm}$ in size were present over his scrotum. No signs of inflammation were present. A diagnosis of Sebaceous cyst was made based on the clinical presentation. Our aim was removal of the Sebaceous cysts with no bleeding \& minimal scar formation. We used an electrosurgical unit with straight dessication needle for the procedure. The area was prepared with spirit. Under local anaesthesia, the cyst was fixed between the index finger \& thumb. With the help of straight dessication needle, the cyst was de-roofed and the contents were evacuated (Fig.2). The base and walls of the cyst were cauterized. There was no bleeding during the procedure and no suturing was required. 


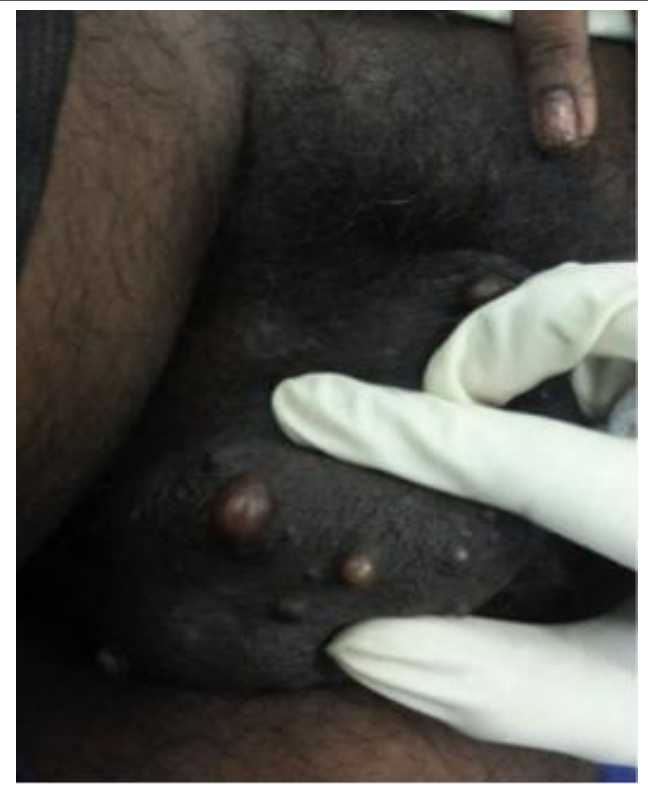

Figure 1 : Multiple cysts over the scrotum

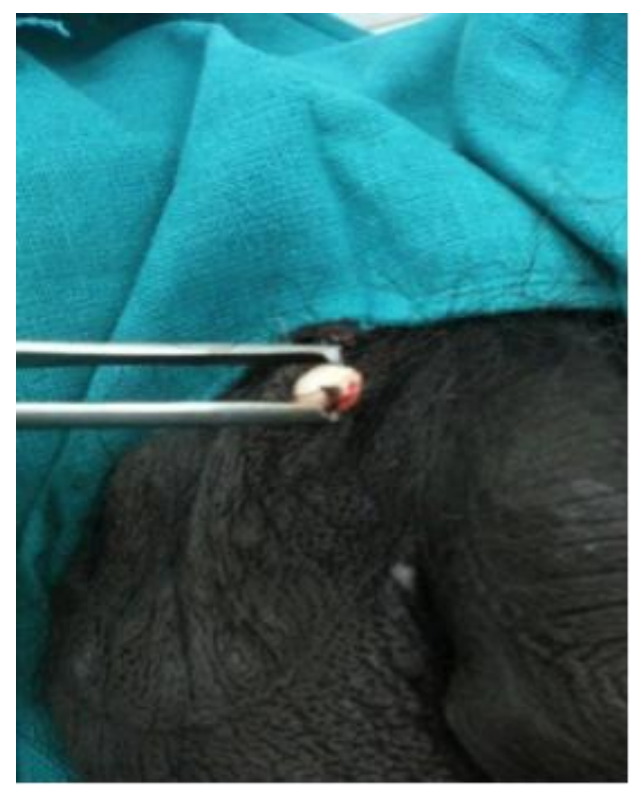

Figure 2: Electrodessication of the sebaceous cyst

\section{RESULT}

There was complete resolution of the lesions following electro-dessication, with no bleeding \& minimal scar formation.

\section{DISCUSSION}

Sebaceous cysts most commonly occur in young and middle aged adults and rarely in children. It can occur as a result of plugged pilo-sebaceous unit. They are commonly multiple, tethered to the epidermis and may have a central keratin filled punctum. Histopathology reveals cysts lined by stratified epithelium with a granular layer and keratinous material, arranged in laminated layers. Surgical excision of a sebaceous cyst is the commonly employed procedure to completely remove the sac and its contents. ${ }^{3}$ For excision, the general approaches used are traditional wide excision, minimal excision, and punch biopsy excision. ${ }^{4}$ Treatment with intralesional steroids, incision \& draining, carbon dioxide laser have all be used as modalities of treatment. Electrodessication is a fast and easy method of sebaceous cyst removal with no bleeding and minimal scarring.

\section{CONCLUSION}

Electrodessication is a fast and easy method of sebaceous cyst removal with no bleeding \& minimal scar formation.

\section{REFERENCES}

1. Cruz AB, Aust JB. Lesions of the skin and subcutaneous tissue. In: Hardy JD, Kukora JS, Pass HI, eds. Hardy's Textbook of surgery. Philadelphia: Lippincott, 1983:319-28.

2. Mohite P, Bhatnagar A. A case of multiple sebaceous cysts over scrotum in a 35 years old male. Internet J Surg 2006; $9: 23$.

3. Klin B, Ashkenazi H (1990). "Sebaceous cyst excision with minimal surgery". American Family Physician 41 (6): 1746-8.

4. Moore RB, Fagan EB, Hulkower S, Skolnik DC, O'Sullivan G (2007). "Clinical inquiries. What's the best treatment for sebaceous cysts?". The Journal of family practice 56 (4): 315-6. 